\title{
The Factors Influencing Bank Credit Capital Accessibility of Enterprises in Hanoi in the Context of the Covid Pandemic
}

\author{
Nguyen Thi Dieu Hien \\ Hanoi University of Industry, Bac Tu \\ Liem District, Hanoi, Vietnam \\ hienntd@haui.edu.vn
}

\author{
Nguyen Thi Mai Huong \\ University of Economics and Business \\ Vietnam National University, Hanoi \\ nguyenthimaihuong21081985@gmail.com
}

\begin{abstract}
Lack of funds and difficult to access to formal loans from banks are problems faced by Vietnamese enterprises in general and Hanoi enterprises in particular. There have been many domestic and international studies on accessing to bank credit capital. While the research works focused on the analysis from a corporate perspective, no specific corporate disclosure has been made in Hanoi, in the context of the Covid pandemic. This study aims to identify the important factors affecting access to bank credit capital in Hanoi, through interviews with 200 customers, and to use a quantitative study method (linear regression). The results showed that there were five factors affecting access to bank credit capital in Hanoi: (1) Economic background, (2) Secured Assets (3) Business Plan, (4) Productivity and (5) the relationship between companies with banks.
\end{abstract}

Index Terms - credit, access to credit capital, enterprise.

\section{INTRODUCTION}

$\mathrm{F}$ UNDING is one of the factors influencing the growth of Vietnamese enterprises in general, as well as those in Hanoi in particular. Among the funds borrowed from banks, credit funds, and the stock market, bank credit has always been the most preferred source of funds by companies due to its advantages such as large loan limits and high guarantees. In the face of the negative impact from the fourth Covid outbreak, demand for bank credit has become more urgent. Statistics show that in the first nine months of 2021, compared to the same period of the previous year, the number of businesses dissolved, decreased by 7.5 percent in registered capital, and decreased by 13.8 percent in labor due to insufficient capital to resume business production [1].

Although the State Bank of Vietnam, financial institutions have implemented a number of measures to support a variety of credit and loan rate cuts, the number of loaned enterprises has not increased significantly. The causes come from many sides, including limitations from the enterprise itself.

The article is the result of a study aimed at identifying factors affecting access to Bank credit capital by enterprises in Hanoi. Based on the research results, the author aims to propose solutions to help increase access to bank credit capital. businesses in Hanoi.

\section{TheoreticAl BASIS}

\section{A. Definition of bank credit}

Bank credit is a relationship in which the right to use capital from the bank is transferred to the customer for a period of time at a certain cost (Nguyen, 2013) [2]. Thus, bank credit consists of three items: (1) transfer of the right to use capital from one person to another, (2) transfer is temporary or takes place during the period and (3) transfer involves costs.

Credit rating is the arrangement for an organization or individual to use a money or commitment to allow the use of a money in principle to be repaid by loan, discount, financial lease, payment coverage, bank guarantee and other credit transactions (Credit Organizations Act, 2010).

\section{B. Types of bank credit}

Short-term credit financing for business: loans with a maturity of 12 months or less. The purpose is to meet the demand for floating capital generated in the production process of the enterprise for raw materials purchase, production costs or consumption needs, payments of small individuals, etc.

Mid- and long-term credit financing for investment: loans with a maturity of more than 12 months. The purpose of borrowing is to repair, repair, replace fixed assets or improve technology, coordinate production processes, renew technology processes and newly build small and large-scale (for medium-term credit) and long-term credit [2].

\section{The role of bank credit in the enterprises}

Bank credit plays a very important role in the supply of funds to the economy, especially to enterprises. Banking credit is a financial lever to support enterprises: Banking credit affects capital transfer: transfer of investment. From companies with high returns and limited funding to those with low returns, bank credit contributes to changing the supply and demand of goods as well as changing the country's economic balance.

Bank credit contributes to the improvement of the efficiency of the Company's use of funds. Because in order to access bank capital, Enterprises need to develop a business production plan, ensure the purposeful use of capital, and efficiently. Bank credit is also a guaranteed factor for a company's continuous business production activities, contributing to the improvement of the efficiency of its use of business funds [2].

\section{Overview}

Access to bank credit capital is influenced by a number of factors. The internal factor of the enterprise is an important factor influencing access to credit capital according to Beck and his colleagues, (2016) [3], Ricardo (2004) [4], Qian (2009) [5], Vo Tri Thanh (2011) [6], Ajagbe (2012) [7], Khalid (2014) [8], Dang Thi Huyen Thuong (2016) [9] Enterprises as well. Operating hours, sales, guaranteed assets. 
They all have a direct impact on the ability of companies to borrow money. Some studies have shown that there is a positive relationship between the size of the enterprise and the ability to borrow funds: Fama and French (2002) [10]; Chen (2004) [11]; Tran Dinh Khieu Nguyen and Ramachandran, (2006) [12], ect.

The Relationship Factor between Enterprises and Banks by authors Gamage Pandula (2011) [13] and Khalid Hassan Abdesamed (2014) [8], Dang Thi Huyen Thuong (2015) [14] pointed out that when Enterprises have a good relationship with the Bank, they have easier access to credit financing. Using the correlation regression method, author Dang Thi Huyen Thuong (2015) showed a positive relationship between the relationship between the enterprise and the bank and the access to capital of the enterprise.

Guaranteed Asset Factor: The larger assets a company has, the easier it is to borrow, due to lower financial risk Mukiri (2016) [15], Dang Thi Huyen Thuong (2015) [14] The study by Nguyen Hong Ha and his colleagues [16] also highlighted the factors influencing access to capital from the characteristics of the enterprise and the "debt repayment" of the enterprise.

Business Alternative Factor: Nguyen Hong Ha (2013) when researching factors affecting the accessibility of small and medium-sized enterprises to credit capital in Tra Vinh province came to the conclusion that a good business plan would make it easier for the business to borrow Banks funds with higher credit limits. According to Ho Ky Minh (2013) [17], developing a business plan is in fact only in response to requests from NH. This reduces bank's confidence in business's management capabilities and debt repayment, affecting business's access to Banks capital.

According to Qian (2009) [5], Tran Dinh Khoi Nguyen and Ramachandran (2006) [12], it is pointed out that the business productivity of a company has a positive effect on the access to capital of the company (Ha Dieu Thuong and Nguyen Thu Nga (2014) [18].

The economic background factor mentioned in the study of Ha Dieu Thuong and Nguyen Thu Nga (2014) suggests that the economic background at the time of the study did not have a significant impact on the accessibility of capital for enterprises

On an overview basis, the author's study develops the following research models:

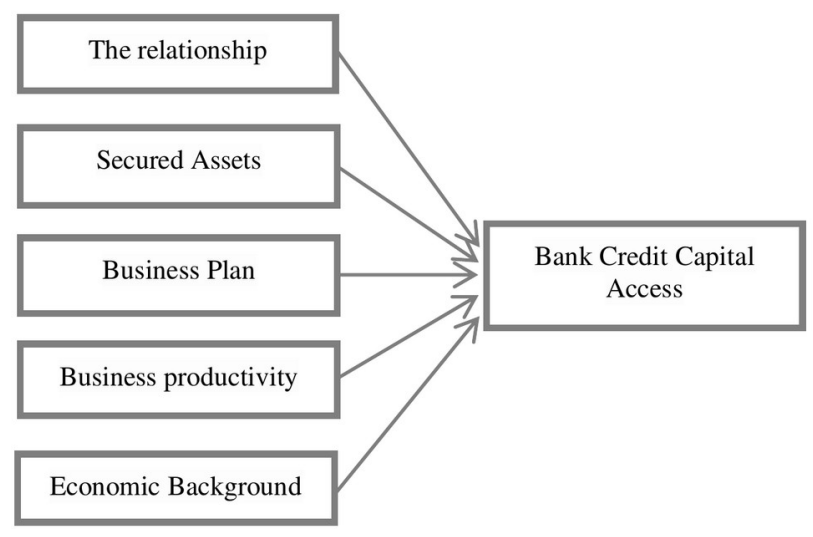

Fig 1 . The study process analysis. Source: Author's simulation
Research hypothesis:

H1: " The relationship" has a positive effect on enterprises access to bank credit in Hanoi.

H2: "Secured Assets" have a positive effect on enterprises access to bank credit in Hanoi

H3: "Business Plan" has a positive impact on enterprises access to bank credit in Hanoi

H4: "Business productivity" has a positive effect on enterprises access to bank credit in Hanoi

H5: "Economic Background" has a positive effect on enterprises access to bank credit in Hanoi

\section{Research Methods and Models}

\section{A. Sample design and data collection}

A Study Using the Most Convenient Sampling Method, Randomized Survey of Companies Operating in Hanoi City Observation sample size to satisfy conditions: $N \times \max [5 \mathrm{x}$, $50+8 \mathrm{~m}]$

+ For EFA exploratory factor analysis, $\mathrm{N} \times 5 \mathrm{x}$ (Hair and Co-operation, 2006

+ For multivariate regression analysis: $\mathrm{N} \times 50+8 \mathrm{~m}$

Therefore, sample size N $[$ [ 5 x 29; $50+8 \times 5]=145$.

The number of samples needs to be greater than 145 , in order for the sample size to be large enough for the author group to distribute 200 copies of questions to enterprises in Hanoi.

\section{B. Research method}

After collection, the questionnaires were reviewed and eliminated from the required questionnaires. The data will then be encrypted, entered, cleaned, and processed using SPSS statistics software. The data analysis process proceeds through the following steps:

(1) Evaluating the reliability of the scale:

To use a scale for analysis Statistics in the study, the reliability of the scale should be verified. The reliability of the scale was tested in a way consistent with the Cronbach's Alpha coefficient. The larger the Cronbach's Alpha coefficient, the more closely the variables observed on the scale are correlated with each other. However, the analysis results for the Cronbach's Alpha coefficient do not tell which observation variables are appropriate or inappropriate, so it is necessary to examine and remove the observation variables that do not match the factors to be measured and those that have a coefficient with the overall correlation (Item Total Corelat).Ion) less than 0.3 will be eliminated (Hoang Trong and Chu Nguyen Mong Ngoc, 2008) [19].

(2) Analysis of EFA Exploration Factors

Remove variables that are not sufficient. Confidence and EFA exploratory factor analysis were conducted to verify the convergence of conceptual and component variables. EFA analysis is a technique used to miniaturize and summarize data. This method is useful for identifying sets of variables required for research problems and is used to find relationships between variables.

Implementation: Since the scales are all unidirectional scales, the Principal Components element extraction method with Varimax rotation is used to produce a rotated factor matrix, which identifies the number of factors extracted and 
the number of initial observation variables belonging to the factors. At the same time, a follow-up analysis is performed by multiplying the factors by the regression method.

(3) Multivariate regression analysis:

Correlation Analysis: Implementation Pearson correlation analysis between independent variables and dependent variables is intended to confirm that there is a linear relationship between dependent and independent variables, indicating that the use of multivariate regression is appropriate between variables. The closer the absolute value of the Pearson coefficient is to 1 , the closer the two variables have a linear correlation. Here we use significance level 2 verification with significance level $\alpha \pm 0.01$ to determine the linear relationship between independent variables and dependent variables before performing regression analysis (Hoang Trong and Chu Nguyen Mong Ngoc, 2008).

Multivariate regression: To model the linear relationship between variables using a linear regression model. This model will describe the form of the relationship and thus help predict the extent of the dependent variable (with accuracy within a limited range) when knowing the value of the independent variable in advance (Hoang Trong and Chu Nguyen Mong Ngoc, 2008).

Construct a regression equation: $Y=\beta_{1} X_{1}+\beta_{2} X_{2}+\ldots+$ $\beta_{5} \mathrm{X}_{5}$

Hypothesis test for the fit of the regression modelWith the data set $\mathrm{i}$ through the corrected coefficient of determination $\mathrm{R} 2$, it is necessary to perform an F-value test to determine the fit of the regression model to the whole.

Hypothesis test for the significance of the regression coefficient by thPartly to affirm or refute the original hypothesis.

\section{Research Results}

\section{A. Assess the reliability of the scale}

First of all, the intrinsic consistency of the scale should be evaluated with the Cronbach's Alpha coefficient to eliminate "waste". Reliability refers to the degree to which measurements can avoid random errors, and to the accuracy and consistency of the results. As a reliability test method, the Cronbach's alpha coefficient is used as a criterion for removing garbage variables to perform a reassessment of the reliability of the scale in each factor. Variables with a correction itemtotal correlation coefficient less than 0.3 are excluded with the condition that the Cronbach's alpha coefficient should be greater than 0.6 . The results are summarized in the table below:

After verifying the reliability of 29 observation variables of 6 factors, all factors were suitable for inclusion in the EFA exploratory factor analysis

\section{B. Exploratory factor analysis}

Exploratory analysis is to understand the components that make up the concepts from the collected data. With this analysis, the variables are freely loaded onto the factors and based on the load coefficient (the correlation coefficient between the variables and the factors) to determine which concepts the variables explain.

In this step, 24 observation variables representing five independent variables are analyzed jointly with Principle
TABLE 1.

Results of the Reliability Evaluation of the Scale

\begin{tabular}{|c|c|c|c|}
\hline Factors & $\begin{array}{l}\text { Observed } \\
\text { variables }\end{array}$ & $\begin{array}{c}\text { Corrected } \\
\text { Item - Total } \\
\text { Correlation }\end{array}$ & $\begin{array}{l}\text { Cronbach's } \\
\text { Alpha if Item } \\
\text { Deleted }\end{array}$ \\
\hline \multirow{5}{*}{$\begin{array}{l}\text { Business } \\
\text { productivity ( } \alpha \\
=0.685)\end{array}$} & BPR1 & 0.427 & 0.641 \\
\hline & BPR2 & 0.438 & 0.640 \\
\hline & BPR3 & 0.466 & 0.623 \\
\hline & BPR4 & 0.380 & 0.664 \\
\hline & BPR5 & 0.503 & 0.606 \\
\hline \multirow{4}{*}{$\begin{array}{l}\text { Secured Assets } \\
(\alpha=0.906)\end{array}$} & SA1 & 0.777 & 0.882 \\
\hline & SA2 & 0.823 & 0.866 \\
\hline & SA3 & 0.796 & 0.875 \\
\hline & SA4 & 0.757 & 0.888 \\
\hline \multirow{5}{*}{$\begin{array}{l}\text { The relationship } \\
\text { between } \\
\text { business and } \\
\text { Bank ( } \alpha= \\
0.847)\end{array}$} & RE1 & 0.512 & 0.852 \\
\hline & RE2 & 0.743 & 0.792 \\
\hline & RE3 & 0.667 & 0.813 \\
\hline & RE4 & 0.627 & 0.824 \\
\hline & RE5 & 0.737 & 0.793 \\
\hline \multirow{4}{*}{$\begin{array}{l}\text { Business Plan } \\
(\alpha=0.850)\end{array}$} & BPL1 & 0.669 & 0.818 \\
\hline & BPL2 & 0.756 & 0.779 \\
\hline & BPL3 & 0.697 & 0.806 \\
\hline & BPL4 & 0.636 & 0.831 \\
\hline \multirow{5}{*}{$\begin{array}{l}\text { Economic } \\
\text { Background ( } \alpha \\
=0.818)\end{array}$} & EB1 & 0.593 & 0.788 \\
\hline & EB2 & 0.558 & 0.797 \\
\hline & EB3 & 0.512 & 0.810 \\
\hline & EB4 & 0.713 & 0.750 \\
\hline & EB5 & 0.676 & 0.763 \\
\hline \multirow{5}{*}{$\begin{array}{l}\text { Bank Credit } \\
\text { Capital Access } \\
(\alpha=0.930)\end{array}$} & EA1 & 0.794 & 0.918 \\
\hline & EA2 & 0.853 & 0.906 \\
\hline & EA3 & 0.856 & 0.906 \\
\hline & EA4 & 0.806 & 0.915 \\
\hline & EA5 & 0.770 & 0.922 \\
\hline
\end{tabular}

Source: Results of model

Component extraction and Varimax rotation. The results of exploratory factor analysis are as follows: KMO coefficient $=0.778$; sig. $=0.000$, components extracted with 5 or more factors, Egenvalue $=1.12$; extractive error reached $70.595 \%$.

TABLE 2.

Componet, Initial Eigenvalue and Total Variance Explained

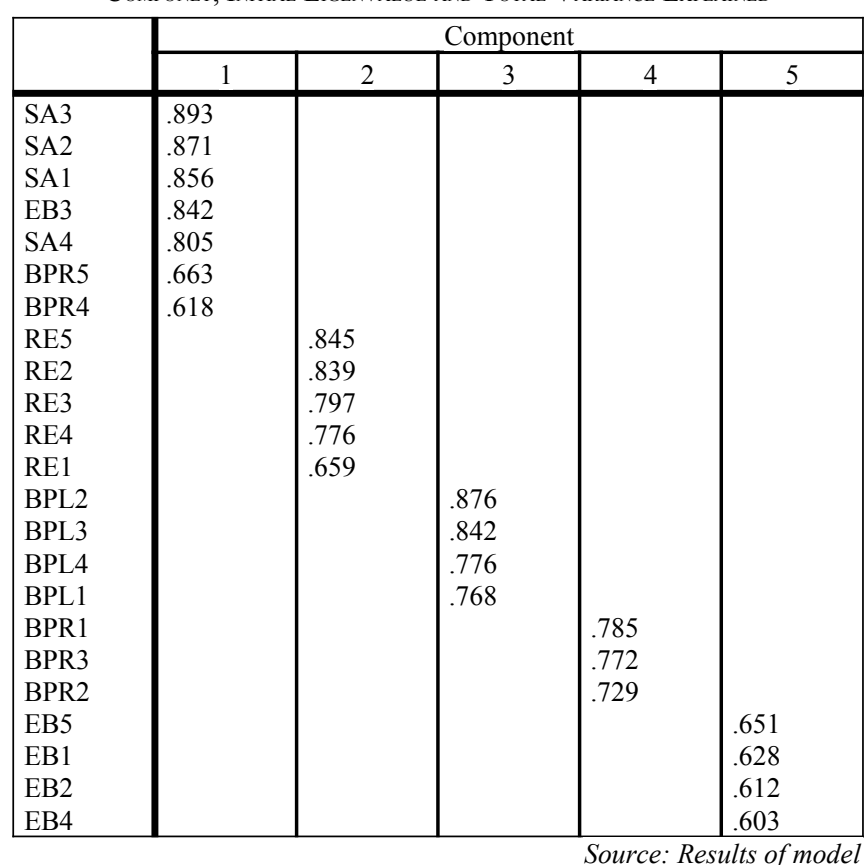

As a result of numerical analysis, variables with a factor load coefficient of 0.55 or more were extracted as five repre- 
sentative factor groups out of 24 observation variables. Includes:

Group 1: The "SA" factor consists of variables: SA1, SA2, SA3, SA4, NSSX4, NSSX5, EB3.

Group 2: The factor "The relationship between Business and Bank (RE) includes variables: RE1, RE2, RE3, RE4, RE5

Group 3: "Business Production Plan (BPL)" factors include BPL1, BPL2, BPL3, BPL4

Group 4: The "Business Productivity (BPR)" factor includes: BPR1, BPR2, BPR3

Group 5: Economic Background (EB) factors include: EB5, EB1, EB2, EB4.

\section{Regression analysis}

To verify the model ngThe author conducts regression analysis to test hypotheses. The results of the regression analysis will show the extent to which the factors "Businessto-Bank Relationship (RE), Business Plan (BPL), Corporate Assured Assets (SA), Business productivity (BPR), and Financial Background (EB) are affected.

Regression analysis is possible. Perform at a significance level of $5 \%$, with the variable selection procedure inserting one-time (enter). Considering the model that shows the linear correlation between the dependent variable and the five independent variables, we construct the following linear regression equation:

\section{$\mathrm{EA}=\beta 1 \mathrm{SA}+\beta 2 \mathrm{RE}+\beta 3 \mathrm{BPL}+\beta 4 \mathrm{BPR}+\beta 5 \mathrm{~EB}$}

Results of $\mathrm{Q}$ analysisThe multivariate variables summarized in Table 4 are as follows:

TABLE 3

Results of Model Fit Assessment

\begin{tabular}{|c|c|c|c|c|c|}
\hline Model & $\mathrm{R}$ & $\begin{array}{l}\mathrm{R} \\
\text { Square }\end{array}$ & $\begin{array}{l}\text { Adjusted R } \\
\text { Square }\end{array}$ & \begin{tabular}{|l} 
Std. \\
Error \\
of the \\
Estimat \\
e
\end{tabular} & $\begin{array}{l}\text { Dur } \\
\text { bin- } \\
\text { Wat } \\
\text { son }\end{array}$ \\
\hline 1 & $.732^{\mathrm{a}}$ & .536 & .520 & $\begin{array}{l}.69275 \\
560\end{array}$ & $\begin{array}{l}1.50 \\
8\end{array}$ \\
\hline
\end{tabular}

ANOVA ${ }^{a}$

\begin{tabular}{|ll|l|l|l|l|l|}
\hline Model & & Sum of Squares & Df & $\begin{array}{l}\text { Mean } \\
\text { Square }\end{array}$ & F & Sig. \\
\hline 1 & $\begin{array}{l}\text { Regressi } \\
\text { on } \\
\text { Residu } \\
\text { al } \\
\text { Total }\end{array}$ & 81.453 & 5 & 16.291 & 33.945 & $.000^{\mathrm{b}}$ \\
& 152.000 & 147 & .480 & & \\
\hline
\end{tabular}

Dependent Variable: Access to Bank Credit Capital

Predictors: (Contant), Economic Background, Productivity Export, Guaranteed , Assets, Business Plan,

Relationship between Business and Banks

Source: Results of model

The adjusted R2 coefficient is 0.536 , that is, the model. 53.6 percent of the total associations that affect "Bank Credit Capital Access (EA)" can be explained.i 46.4 percent are affected by non-modular variables. Figure and random error.

Durbin Watson test results for coefficient $\mathrm{d}=1.508$, located. in about a mile and a mile

Hypothesis test for fit of model: We have F.5; 152) = 33.945; $\mathrm{Sig}=0.000 \pm 0.05$. In this way, the constructive linear model fits the whole.
The results of the regression model shown in Table 5 are as follows.

TABLE 4

COEFFICIENTS

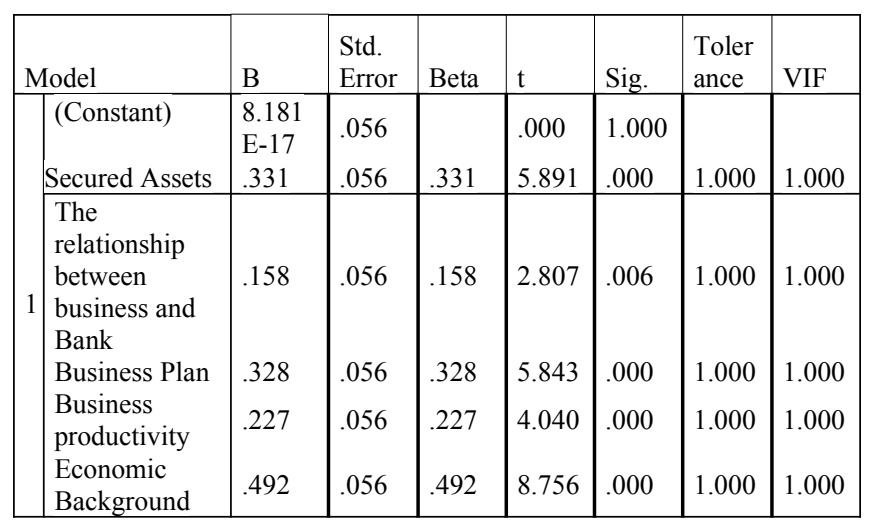

a. Dependent Variable: K enterprises' access to bank credit in Hanoi Source: Results of model

As a result of the analysis, the VIF error magnification coefficient of each independent variable was all required (less than 10), so the multicollinearity phenomenon did not occur or was insignificant in this study.

The results of the regression analysis also show the verification values of five factors: "Secured Assets (SA), Relationship between Business and banks (RE), Business Plan (BPL), Productivity Capacity (BPR), and Contingency.Economic Photo (EB)" is statistically significant because the significance level is less than 0.01. Therefore, "Secured Assets (SA), Relationship between Business and banks (RE), Business Alternatives (BPL), Productivity (BPR), and Economic Background (EB) have an effect on "Bank Credit Capital Access (EA).

Check for residual with a standard distribution: when the model is incorrectly used, or the method is not constant, the number of residual parts is not large enough for analysis, the residual may not be distributed.Implicit. Therefore, a survey on the distribution of residual parts is needed, which is done by constructing histograms and P-Plots. It is also important to note that it is not reasonable to expect that the observation residuals have a completely standard distribution because there are always differences in sampling, even if the real error has a standard distribution in the whole, the observation sample has only a standard approximation distribution.

\section{Histogram}

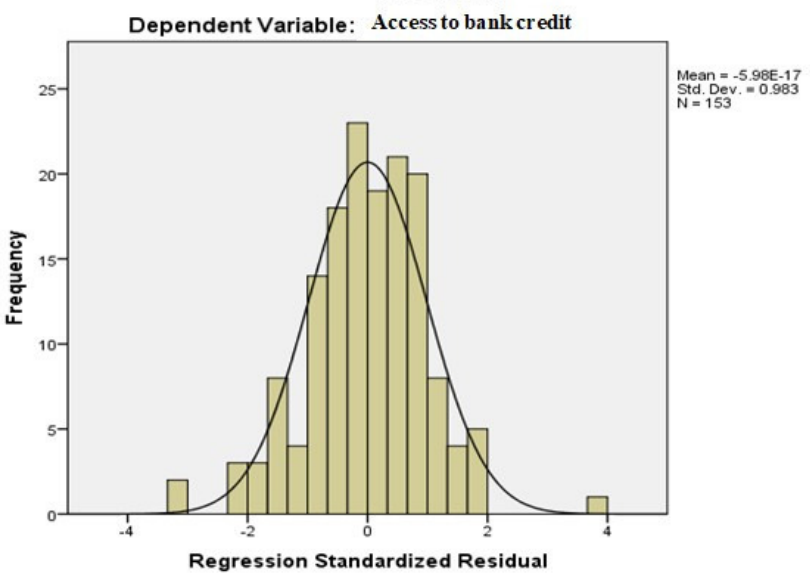

Fig 2 . Frequency Histogram 
From the graph in Figure 2, we see that the standard deviation (Std.Dev) in the regression model is 0.983 approximating to 1 , and the mean is close to 0 . Because it is not possible to expect that the observed residual to have a complete standard distribution because there are differences in sampling, or when the real error has a standard distribution in the whole, the residual has only a standard approximation distribution. Therefore, it can be concluded that the standard distribution hypothesis is not violated.

Normal P-P Plot of Regression Standardized Residual

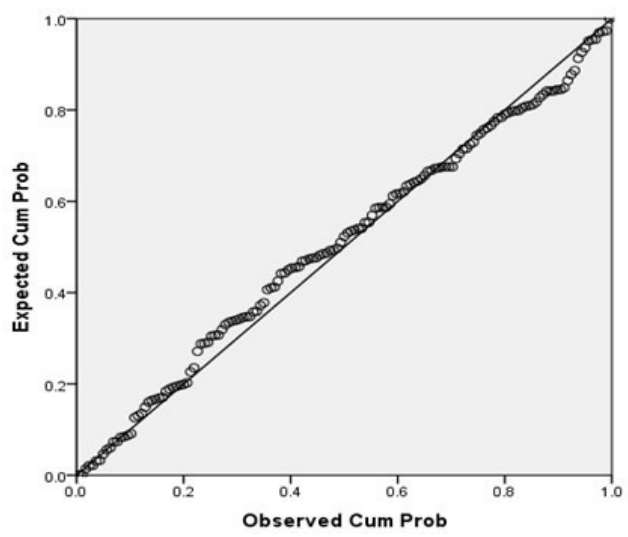

Fig 3. P - P Plot Histogram

Source: Results of model

The P-P Plot shows that the observed variables do not scatter too far from the expected straight line in the model, so we can argue that the standard distribution hypothesis is not violated.

After examining the violation of the assumptions in regression model analysis, the results of the regression model of the sample can use estimates for the overall regression coefficients. The accepted regression equation is as follows:

$\mathrm{EA}=0.331 \mathrm{SA}+0.158 \mathrm{RE}+0.328 \mathrm{BPL}+0.227 \mathrm{BPR}+$ $0.492 \mathrm{~EB}$

Based on the results of the regression analysis, we found that the most influential factor in "Bank Credit Capital Access (EA)" was the "Economic Background (EB), followed by "Secured Assets (SA)", and "Business Plan (BPL)", "Business productivity (BPR)" and finally, "Relationship Between business with Banks (RE)"

Based on the results of multivariate regression analysis (Table 5), the hypotheses tested are as follows: The independent variable "Secured Assets (SA)" with a standardized regression coefficient $\beta=0.12$ is significant.If the other factors remain unchanged, on average, when "Secured Assets (SA)" increases by 1 unit of standard deviation, " Bank Credit Capital Access (EA)" increases by 0.32 units of standard deviation $(33.1 \%)$ and $\mathrm{Sig}=0.000 \times 0.01$ proves that this conclusion is statistically significant."Bank Credit" is accepted

The independent variable " The relationship between business and Bank" (RE) with a standardized regression coefficient of $0=0.12$ means that when other factors remain unchanged, " The relationship between business and Bank" (RE) increases by 1 unit of standard deviation, "Bank Credit Capital Access " increases by $0 \%$ on average. $006 \pm 0.01$ proved this conclusion statistically significant, and therefore the hypothesis that "the relationship between Business and banks has a positive effect on access to bank credit capital" was accepted.

The independent variable "Business Plan (BPL)" with a standardized regression coefficient of $328=0.13$ means that when other factors remain unchanged, on average, when "Business Plan (BPL)" increases by 1 unit of standard deviation, "Bank Credit Capital Access (EA)" increases by $0.32 \%$. This is statistically significant, so the hypothesis that "business plans have a positive effect on access to bank credit capital" is accepted.

The independent variable "Business productivity (BPR)" with a standardized regression coefficient of có $=0.227$ means that the average deviation of "Business productivity (BPR)" to 1 unit of standard deviation increases "Bank Credit Capital Accessibility (EA) by $0.227 \%$ " when other factors remain constant.y is statistically significant, so the hypothesis that "productivity has a positive effect on access to bank credit" is accepted.

The independent variable "economic background (EB)" with a standardized regression coefficient $49=0.492$ means that when other factors remain unchanged, on average, when "economic background (EB)" increases by 1 unit of standard deviation, "Bank Credit Capital Access (EA) 490.2\%" increases. is statistically significant, so the hypothesis: "The economic background has a positive effect on access to bank credit" is accepted.

\section{In Conclusion}

Based on theoretical and practical research, we see that enterprises in Hanoi want access to credit capital from banks. However, access to these funds by companies is difficult, in addition to the difficulties inherent in them: small businesses, small guarantees, weak business Business productivity, insufficient clarity, insufficient information, and lack of confidence in banks. Debt and corporate development are also attributable to the bank's credit policy mechanisms such as interest rates, borrowing procedures, loan maturities and loan review periods, which also contribute to increasing difficulties for companies in accessing capital.

Through the use of the regression analysis method, the study identified the factors affecting the accessibility of bank credit capital of enterprises in Hanoi. The study found that five factors influencing access to bank credit capital were summarized in order of strong influence: "economic background (EB), "relationship between Business and banks," "Secured Assets (SA), and "Business productivity (BPR)." These results contribute to enhancing coordination among businesses, banks, industries and related organizations in the implementation process so that business can access bank credit more easily.

\section{REFERENCES}

[1] General Statistics Office of Vietnam, The number of new start-up registrations plunged in September 2021, 2021,//www.gso.gov.vn/dulieu-va-so-lieu-thong-ke/2021/10/doanh-nghiep-dang-ky-thanh-lapmoi-sut -giam-manh-trong-thang-9-va-9-thang-nam-2021/

[2] V. T Nguyen, "Banking Credentials Textbook”, Ha noi, Publisher statistics, 2013.

[3] T. Beck, \& A. Demirguc-Kunt, "Small-medium enterprise sector: access to finance as a growth constrain" $t$, 2006, Journal of Finance and Banking,. 30(11), 2931-2943. 
[4] Ricardo N. Bebczuk, "What Determines the Access to Credit by SMEs in Argentina?", 2014, Department of Economics, Universidad Nacional de La Plata, Argentina, 48, pp15-30.

[5] Y. Qian,, Y. Tian, and T.S Wirjanto, "Do Chinese publicly listed companies adjust their capital structure toward a target level?", 2009, China Economic Review, Vol. 20, No. 4, pp. 662676.

[6] V. T Thanh, Small and Medium enterprise access to finance in Vietnam, 2011, Central Institute for Economic and Management, Chapter 6.

[7] F. A Ajagbe, "Features of small scale enterpreneur and access to credit in Nigeria: a microanalysis", 2012, American Journal Of Social And Management Sciences, Pages 39- 44.

[8] H. Khalid Abdesamed and K.A Wahab, "Financing of Small and Medium Enterprises (SMEs) in Libya: Determinants of Accessing Bank Loan”, 2014 Middle-East Journal of Scientific Research, 21 (1), pp. 113-122, 2014 ISSN 1990-9233

[9] D. T. H Thuong, "Factors affecting access to loans by small and medium-sized enterprises in Hanoi", 2016, Doctor of Economics Philosophy, Foreign Trade University, Ha noi.

[10] E. F Fama and K. R French, "Testing Trade-Off and Pecking Order Predictions About Dividends and Debt”, 2002, Review of Financial Studies, Vol. 15, No.1, pp. 1-336.

[11] J. J Chen, "Determinants of capital structure of Chinese-listed companies”. 2004, Journal of Business Research, Vol. 57, pp. 13411351 .
[12] K. N Tran Dinh, \& Ramachandran, N., "Capital Structure in Small and Medium-sized Enterprises", 2006, ASEAN Economic Bulletin, Vol. 23, No. 2, pp. 192-211.

[13] Gamage and Pandula, "Bank Finance For Small And Medium-Sized Enterprises In Sri Lanka: Issues And Policy Reforms”, 2015. Studies in Business and Economics. Vol. 18, No. 1, pp. 98 - 112.

[14] D. T. H Thương, "Factors Influencing Small and Medium Businesses' Access to Loans", 2015, Economic and Forecasting Journal of Forecasts, Vol.10, No.1, pp..15- 18.

[15] W. G Mukiri, "Determinants of access to Bank credit by micro and small enterprises in Kenya", 2011, Beacon Consultant Service, Kenya.

[16] N. H Ha, H. T. N Tuyen, D.C. Binh "Analysis of Factors affecting access to credit capital of small and medium-sized enterprises in Tra Vinh Province", 2013. Social and Humanities Press , Vol. 09, No.1, pp. $37-45$.

[17] H. K Minh, V. T. T Anh, L. T. H Cam, “An Assessment of Corporate Access to Banking in South Central Coast and Central Highlands ",2013, Da Nang Journal of Social Economy, Vol.33, pp. 3339.

[18] H. D Thuong, N. T Nga, “a study on access to bank capital by small and medium-sized enterprises in Thua Thien Hue, 2014, Journal of Economics and Development, Vol. 202, No. 2 , pp. 45 - 57.

[19] H. Trong, C. N. M Ngoc, "Analyzing Research Data with SPSS”, Ho Chi Minh city, Publishing company Hong Duc, 2008. 